\title{
PARENTAL ATTACHMENT AND PHYSICAL INTIMATE PARTNER VIOLENCE IN YOUNG ADULTS: MEDIATIONAL ROLE OF DYSFUNCTIONAL ATTITUDES
}

\author{
Chloe Cherrier ${ }^{1}$, Catherine Potard ${ }^{2}$, Emmanuel Rusch $^{3}$, \& Robert Courtois ${ }^{1}$ \\ ${ }^{1}$ EE 1901 QualiPsy, University of Tours (France) \\ ${ }^{2}$ EA 4638 LPPL, University of Angers (France) \\ ${ }^{3}$ EA 7505 EES, University of Tours (France)
}

\begin{abstract}
Introduction. Physical violence (PV) is a form of intimate partner violence. It has serious consequences on the population health. Previous studies have linked PV victimization with parental attachment. However, little is known about dysfunctional attitudes and this relationship. This study aimed to evaluate dysfunctional attitudes as a mediator between parental attachment and PV victimization of young adults. Methods. Cross-sectional design was used to study 915 participants aged 18-30 years old with 84.8\% women, the average age was $23.59 \pm 3.35$ years old and the average level of education 15.07 years \pm 2.70 . Several self-report questionnaires were used: the Revised Conflict Tactics Scale 2 (CTS2; only physical assault subscale), the Inventory of Parent and Peer Attachment (IPPA) and the Dysfunctional Attitude Scale (DAS). Results. Two-hundred and six participants $(21.1 \%)$ were victims of PV during their lifetime. They had more dysfunctional attitudes and an insecure attachment to parents compared to PV non-victims. Our results showed a partial and weak mediation of dysfunctional attitudes between attachment to mother and PV victimization. There was not mediation for attachment to father. Conclusions. An insecure parental attachment was associated with more dysfunctional attitudes and a risk to be victims of PV for the young adults. However, the dysfunctional attitudes only partially mediate the link between parental attachment to mother and PV victimization.
\end{abstract}

Keywords: Physical violence, dysfunctional attitudes, parental attachment, young adults.

\section{Introduction}

Intimate partner violence is a current worldwide public health problem. It can take different forms: psychological, physical and sexual. Physical violence (PV) associated with other forms of violence, has serious consequences on mental and physical health. It is defined as "the intentional use of physical force with the potential for causing death, disability, injury, or harm" (Saltzman et al., 1999) in a romantic relationship. It can be used by the intimate partner as an inappropriate strategy to keep control of the relationship. PV victims are in a subjugated relationship and do not always have individual resources to get out of it. In France, women are especially concerned with 154000 PV victims in 2018 (MIPROF, 2019). According to ENVFF (2001), 20\% of intimate partner violence are 20-24 years old. Young adult victims of intimate partner violence are exposed to a risk of re-victimization in adulthood (e.g., Smith, White, \& Holland, 2003). During this stage, the discovering of oneself and others contribute to the construction of one's future identity and represents an important developmental period.

Many studies have examined vulnerability factors for physical intimate partner violence (Stith, 2003) and one of the most established links is parental attachment. Bowlby's theory (1980) is based on the fact that every human being continually tries to develop bonds of attachment with those around him in order to survive. Classically three styles of parental attachment were described: secure, insecure-avoidant and insecure anxious-ambivalent (Ainsworth, Blehar, Waters, \& Wall, 1978). A secure attachment to parents for young adults allows positive self-interpersonal relationships. A young adult with an insecure attachment to parents finds it difficult establish intimate relationships with others. He will not know how to put the right emotional distance with his partner (either by being too close or by being too distant). Also, according to the family environment during childhood, the individual has constructed representations of himself, of others and of the world around him called internal working models (Pietromonaco \& Barrett, 2000). They may change throughout life, but are predefined during childhood and are linked to the type of parental attachment. Miljkovitch and Cohin (2007) showed that parental attachment and working models in childhood are lifelong models and therefore would continue throughout adulthood, especially in couples. 
Adults with an insecure attachment in their couple have the same working models as in childhood. However, adults secure tend to adapt their representations to those of their partners. If these "encoded schemes" are negative, they can be the source of various psychopathologies. Beck's cognitive theory (1976) postulates that childhood maladaptive beliefs will be retained in adulthood and will lead to dysfunctional attitudes when stressful events occur. Kaygusuz's study (2013) has shown that young adults who have negative beliefs about themselves and others have non-harmonious and conflicting relationships. The link between parental attachment and dysfunctional attitudes has been largely developed in clinical psychology as a predictor of depression (Lee \& Hankin, 2009; Otani, Suzuki, Matsumoto, \& Enokido, 2016; Roberts, Gotlib, \& Kassel, 1996). However, up to now, very few studies have explored the links with intimate partner violence, especially PV. We hypothesize that parents' insecure attachment will lead to inappropriate beliefs about themselves and about others resulting in dysfunctional attitudes that can be a vulnerability factor to PV. Therefore, the present study aims to examine the mediating role of dysfunctional attitudes between parental attachment and physical intimate partner violence among young adults.

\section{Methods}

\subsection{Procedures and participants}

The current study followed a cross-selectional design. A self-administered online questionnaire intended for young adults aged 18-30 years old was distributed through various networks (university, associations, professionals, etc.). The inclusion criteria's in this study were to have been involved at least once in a romantic relationship during one's life and to have been in contact with at least one of one's parents $^{1}$. The sample consisted of 915 participants including $84.8 \%$ women, with an average age 23.59 years old \pm 3.35 and an average level of education of $15.07 \pm 2.70$.

\subsection{Measures}

The Revised Conflict Tactics Scale 2 (CTS2; Straus, HambyandBoney, 1995 translated by Lussier, 1998) was used to measure the level of conflict and abuse between partners. We only used the physical assault subscale and the form for victims (39 items). The scoring used is the authors' one in dichotomous (yes: victims of at least one act of PV during his lifetime, no: non-victims of PV during his lifetime). The Inventory of Parent and Peer Attachment (IPPA; Armsden and Greenberg, 1987 translated by Vignoli and Mallet, 2004) measures young adults' mother and father attachments. It is composed of 28 items and measured through three dimensions: communication, trust and alienation. From these dimensions, the scale was categorized into three attachment styles according to Vivona (2000). In this study only the secure and insecure styles were studied. For attachment to mother $14 \%$ of the data could not be coded, the same for the father. These proportions are similar to those of Vivona. The Dysfunctional Attitude Scale (DAS; Weissman 1980 translated by Bouvard, 1994) assesses the level of dysfunctional attitudes according to the hypothesis of Beck's cognitive theory. We used the form A of the scale which includes 29 items. A high score indicates greater endorsement of cognitive biases.

\subsection{Statistical analysis}

Data were analyzed with the use of SPSS version 25. Victims were divided into two groups: victims of PV and non-victims of PV. Independent sample $t$-tests were used to compare the participants characteristics between two groups. A series of logistic and linear regressions were conducted, based on the steps proposed by Baron and Kenny (1986) to examine whether dysfunctional attitudes mediate the relationship between parental attachment and PV. Models were tested separately for mother and father attachments.

\section{Results}

Bivariate statistics. There was not significative difference between the groups of non-victims of $\mathrm{PV}$ and victims of PV according to age, sex and level of education. Victims of PV were $21.1 \%(n=206)$. They had a more insecure style of attachment to mother $\left(53.5 \%, X^{2}=13.27, p<.001\right)$, and the same for the attachment to father $\left(52.4 \%, X^{2}=12.35, p<.001\right)$ than non-victims. Victims also showed a higher total score of dysfunctional attitudes $(M=99.6 \pm 25.6 ; t=-3.20, p<.01)$ than non-victims $($ Table 1$)$. Moreover, it was found that victims of PV had a majority of higher scores of dysfunctional attitudes than non-victims of PV (except for the insecure style to the father). Especially, the victims with an insecure style to their mother had more dysfunctional attitudes $(M=103.77 \pm 28.65 ; t=-2.35, p<.05)$ than non-victims of PV with an insecure style (Table 2).

\footnotetext{
${ }^{1} 19$ participants were not in contact with their mother and 115 participants were not in contact with their father
} 
Table 1. Comparison of independent variables between victims of $P V$ group and non-victims of $P V$ group.

\begin{tabular}{|c|c|c|c|c|c|c|}
\hline & \multicolumn{2}{|c|}{ Non-victim of PV } & \multicolumn{2}{|c|}{ Victim of PV } & & \\
\hline Variables & $n$ & $M \pm \mathrm{SD}$ or $\%$ & $n$ & $M \pm \mathrm{SD}$ or $\%$ & $X^{2}$ & $t$ \\
\hline Attachment to mother & 593 & & 172 & & $13.27 * * *$ & \\
\hline Secure & 368 & 62.1 & 80 & 46.5 & & \\
\hline Insecure & 225 & 37.9 & 92 & 53.5 & & \\
\hline Attachment to father & 531 & & 142 & & $12.35 * * *$ & \\
\hline Secure & 338 & 63.7 & 70 & 47.6 & & \\
\hline Insecure & 193 & 36.3 & 72 & 52.4 & & \\
\hline Dysfunctional attitudes & 709 & $92.45 \pm 28.86$ & 206 & $99.58 \pm 25.58$ & & $-3.20 * *$ \\
\hline
\end{tabular}

Table 2. Comparison of dysfunctional attitudes and parental attachment between victims of PV group and non-victims of $P V$ group.

\begin{tabular}{lccccc}
\hline & \multicolumn{5}{c}{ Dysfunctional attitudes } \\
\hline & \multicolumn{1}{c}{ Non-victim of PV } & Victim of PV & \\
\hline Variables & $n$ & $M \pm \mathrm{SD}$ & $n$ & $M \pm \mathrm{SD}$ & $t$ \\
\hline Attachment to mother & 593 & & 172 & & \\
\hline Secure & 368 & $88.38 \pm 28.13$ & 80 & $95.90 \pm 24.69$ & $-2.21^{*}$ \\
\hline Insecure & 225 & $95.91 \pm 27.74$ & 92 & $103.77 \pm 25.35$ & $-2.35^{*}$ \\
\hline Attachment to father & 531 & & 142 & & \\
\hline Secure & 338 & $88.29 \pm 27.94$ & 70 & $96.8 \pm 28.06$ & $-2.31^{*}$ \\
\hline Insecure & 193 & $100.02 \pm 28.35$ & 72 & $103.32 \pm 28.65$ & $n s$ \\
\hline
\end{tabular}

Data are presented as mean \pm standard deviation; ns: not significant; ${ }^{*} p<.05,{ }^{* *} p<.01,{ }^{* * *} p<.001$.

Mediation analysis. The mediating models remained significant after adjusting for age, sex and education. The first step examined whether dysfunctional attitudes were associated with PV. There was a significant association between attachment to mother and $\mathrm{PV}(\mathrm{OR}=1.85,95 \% \mathrm{CI}=[1.31 ; 2.61], p<.001)$ and attachment to father and PV $(\mathrm{OR}=1.87,95 \% \mathrm{CI}=[1.29 ; 2.72], p<.01)$. In the second step, there was significant associations between parental attachment and dysfunctional attitudes (mother: $\beta=.16, p<.001$; father: $\beta=.21, \mathrm{p}<.001)$. In the third step, higher dysfunctional attitudes were associated with PV victimization (mother: $\mathrm{OR}=1.01,95 \% \mathrm{CI}=[1.00 ; 1.02], p<.01$; father: $\mathrm{OR}=1.01,95 \% \mathrm{CI}=[1.00 ; 1.02]$, $p<.05)$. In the final step, when dysfunctional attitudes were included in the regression model, association between attachment to mother and PV decreased $(\mathrm{OR}=1.71,95 \% \mathrm{CI}=[1.21 ; 2.43], p<.01)$, indicating partial mediation. For attachment to father, when dysfunctional attitudes were included in the regression model, association with $\mathrm{PV}$ did not change $(\mathrm{OR}=1.71,95 \% \mathrm{CI}=[1.17 ; 2.51], p<.01)$, indicating no mediation.

Figure 1. Mediation model of dysfunctional attitudes between parental attachment and PV.
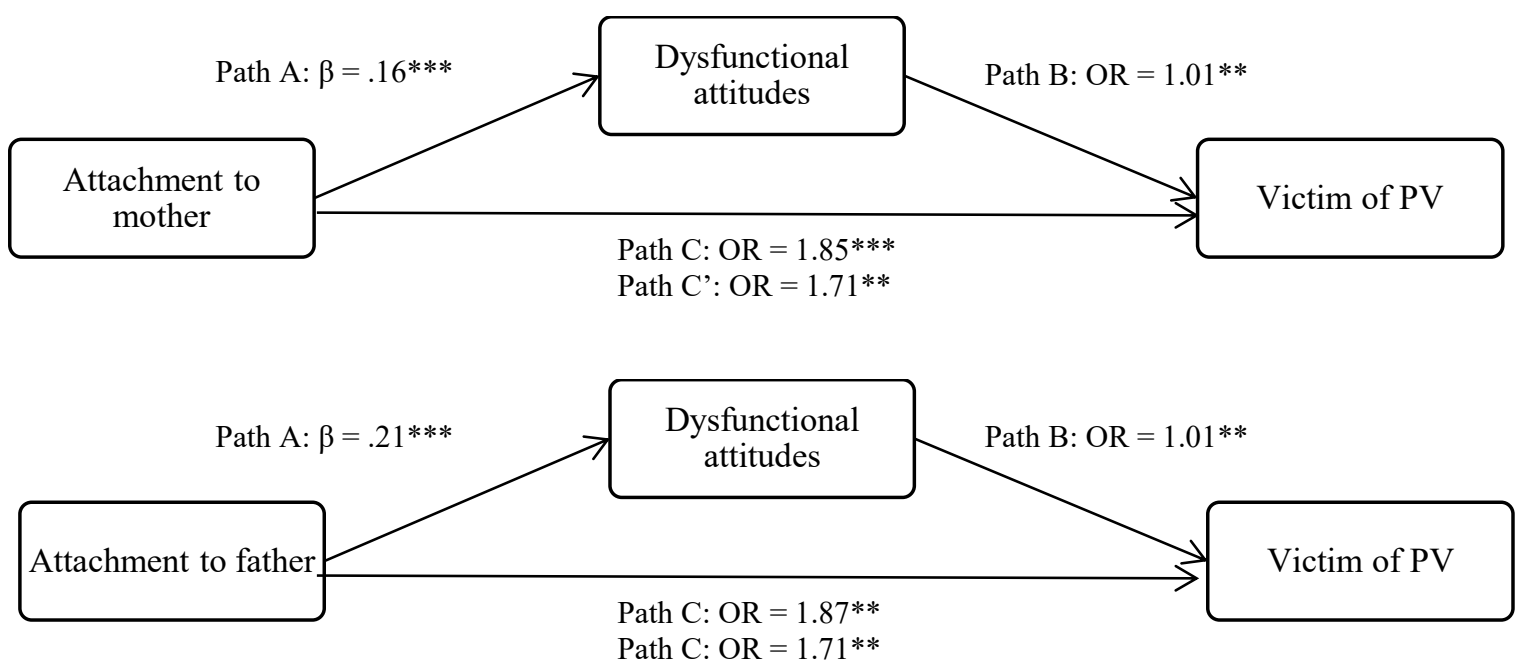

$\beta=$ standardized coefficient; $\mathrm{OR}=$ odds ratio; $* p<.05,{ }^{* *} p<.01,{ }^{* * *} p<.001$. Path A: Test of whether parental attachment is a significant predictor for dysfunctional attitudes. Path $\mathrm{B}$ : Test of whether dysfunctional attitudes are a significant predictor for the PV victimization. Path C: Test of whether parental attachment is a significant predictor for the PV victimization. Path $\mathrm{C}^{\prime}$ : Test of whether parental attachment and dysfunctional attitudes together are significant predictors for the PV victimization. 


\section{Discussion}

The present study found that $21.1 \%$ young adults have already been victims of at least one act of PV in their lifetime by one of their partners. The prevalence of victims of PV varies from $9 \%$ to $49 \%$ depending on the studies (WHO, 2010). It was interesting here to study the history of PV in the life of young adults since we wanted to see if negative beliefs built up from childhood could at some point in life be a factor of vulnerability to PV. The results showed that an insecure attachment to the father or mother increased the risk of being victim of PV at least once in this lifetime by 1.8 times compared to the secure style attachment. Parental attachment is an important vulnerability factor for PV victimization (Velotti, Zobel, Rogier, \& Tambelli, 2018). Young adults with insecure parental attachment have a greater propensity to have dysfunctional attitudes. The insecure does not cause psychopathologies directly but depends on having negatives attachment experiences which are linked to a negative self-model. In this study, dysfunctional attitudes seem to be little associated with victimization of PV (OR close to 1) although this association is significant. However, when the groups of victims are compared, victims have significantly more dysfunctional attitudes than non-victims. The dysfunctional attitudes have a very partial mediating effect on the link between attachment to mother and PV victimization, but not for attachment to father. In the literature, this mediation is well established with depression (Lee \& Hankin, 2009; Otani et al., 2016; Roberts et al., 1996). To obtain similar results with PV victimization, further complementary analyses are required.

Limits. First, the scoring utilized to evaluate PV was dichotomous and therefore it could not be possible to test the indirect effect of mediation (Sobel test). It would be a good thing to repeat the statistical analyzes via a structural equation model. Participants were essentially female, which is not representative of the population. For the sake of feasibility, we chose to focus only on PV victims, but it would be interesting to study the bidirectionality between perpetrators and PV victims, especially among young adults (Glowacz \& Courtain, 2017; Palmetto, Davidson, Breitbart, \& Rickert, 2013). Finally, in order to generalize the results, the design could be tested longitudinally.

Implications. In the literature, no studies have searched the link between physical intimate partner violence and dysfunctional attitudes. Indeed, if young adults have insecure working models, they will tend to have dysfunctional attitudes and to turn to partners with the same profile, thus increasing the risk of dysfunctional relationships. This mediation between parental attachment and PV, through dysfunctional attitudes, indicate that failing to act on the attachment of young adults to their parents, we can try to act on their beliefs and representations in an attempt to deconstruct them. Thus, this research provides a first reflection to support interventions in the universal prevention of PV and more generally in intimate partner violence.

\section{Conclusions}

An insecure parental attachment and having dysfunctional attitudes can be factors of vulnerability to victimization of PV. When these results are crossed, dysfunctional attitudes appear to be only a partial and weak mediator of attachment to the mother and victimization of PV in young adults.

\section{References}

Ainsworth, M. D. S., Blehar, M. C., Waters, E., \& Wall, S. N. (1978). Patterns of attachment: A psychological study of the strange situation. Hillsdale, NJ: Lawrence Erlbaum Associates.

Baron, R. M., \& Kenny, D. A. (1986). The Moderator-Mediator Variable Distinction in Social Psychological Research. Conceptual, Strategic, and Statistical Considerations. Journal of Personality and Social Psychology, 51(6), 1173-1182.

Beck, A. T. (1976). Cognitive therapy and the emotional disorders. New York, NY: International Universities Press.

Bowlby, J. (1980). Attachment and loss: Vol. 3, Loss sadness, and depression. New York, NY: Basic book.

ENVFF. (2001). Nommer et compter les violences envers les femmes: une première enquête nationale en France. Population \& Sociétés, 364, 4.

Glowacz, F., \& Courtain, A. (2017). Violences au sein des relations amoureuses des adolescents et jeunes adultes : une réalité à ne pas négliger. Champ Pénal, XIV.

Lee, A., \& Hankin, B. L. (2009). Insecure attachment, dysfunctional attitudes, and low self-esteem predicting prospective symptoms of depression and anxiety during adolescence. Journal of Clinical Child and Adolescent Psychology, 38(2), 219-231.

Miljkovitch, R., \& Cohin, E. (2007). L'attachement dans la relation de couple: une continuité de l'enfance. Dialogue, 1(175), 87-96. 
MIPROF. (2019, November). La lettre de l'observatoire national des violences faites aux femmes. Numéro 14. Observatoire National Des Violences Faites Aux Femmes, 28. Retrieved from https://www.stopviolences-femmes.gouv.fr/data/ONVF $\mathrm{n}^{\circ} 14$ - Violences au sein du couple et violences sexuelles_novembre 2019.pdf

Otani, K., Suzuki, A., Matsumoto, Y., \& Enokido, M. (2016). Link of dysfunctional attitudes with the negative self-model. Annals of General Psychiatry, 15(1), 1-5.

Palmetto, N., Davidson, L. L., Breitbart, V., \& Rickert, V. I. (2013). Predictors of physical intimate partner violence in the lives of young women: Victimization, perpetration, and bidirectional violence. Violence and Victims, 28(1), 103-121.

Pietromonaco, P. R., \& Barrett, L. F. (2000). The Internal Working Models Concept: What Do We Really Know about the Self in Relation to Others? Review of General Psychology, 4(2), 155-175.

Roberts, J. E., Gotlib, I. H., \& Kassel, J. D. (1996). Adult Attachment Security and Symptoms of Depression: The Mediating Roles of Dysfunctional Attitudes and Low Self-Esteem. Journal of Personality and Social Psychology, 70(2), 310-320.

Saltzman, L. E., Fanslow, J. L., Mcmahon, P. M., Shelley, G. A., Gerberding, J. L., Binder, S., ... Lord, B. B. (1999). Intimate partner violence surveillance: Uniform definitions and recommended data elements, version 1.0. Atlanta. Retrieved from http://www.cdc.gov/ncipc/

Smith, P. H., White, J. W., \& Holland, L. J. (2003). A longitudinal perspective on dating violence among adolescent and college-age women. American Journal of Public Health, 93(7), 1104-1109.

Velotti, P., Zobel, S. B., Rogier, G., \& Tambelli, R. (2018). Exploring relationships: A systematic review on Intimate Partner Violence and attachment. Frontiers in Psychology, 9(JUL).

Vivona, J. M. (2000). Parental attachment styles of late adolescents: Qualities of attachment relationships and consequences for adjustment. Journal of Counseling Psychology, 47(3), 316-329.

WHO. (2010). Preventing intimate partner and sexual violence against women. Taking action and generating evidence. Geneve. Retrieved from https://www.who.int/violence_injury_prevention/publications/violence/9789241564007_eng.pdf 